vice vers $\hat{a}$; but, though it is certain that the force of the heart beat may be modified ccördinately with modifications of peripheral resistance, rising and falling with this latter, the modifications in arterial pressure which follow modifications in peripheral resistance may, theoretically at all events, take place quite independently of variations in the force of the heart beat, as is evident from the foregoing considerations. This fact, though set forth in the physiological text-books, is not sufficiently insisted on, for it has, as will be seen, most important pathological applications. Its truth may be demonstrated by a very simple experiment. Place npon a shelf, say $10 \mathrm{ft}$. high, a reservoir of water such as is used by surgeons in washing out cavities, and allow the water to flow out through a long piece of drainage tubing open at its free end. Let now the tension in the tube be carefully estimated by the fingers. If while this is being done the ontlet be suddenly narrowed by compression a shock will be immediately felt, the tube will become distended, and greater compression will now be needed to obliterate the lumen; or if, instead of using the fingers, a water manometer be attached to the side of the tube (the glass tube of a urinometer will answer the purpose admirably) the water will immediately rise on narrowing the outlet. This sudden increase of lateral pressure is manifestly due to the increase in resistance, and to that solely, seeing that the driving force, far from becomirg greater, bas been stearily diminishing throughout the experiment; in other words, it is due to the conversion of forward into lateral energy. This being so, it is evident that, theoretically at all events, arterial blood pressure may vary very considerably, independently of any modification in the beat of the heart, and it suggests that arterial pressure may be good while the left ventricle is contracting with only moderate force, or, to put it in another way, that good arterial tension does not necessarily imply the normal standard of cardiac strength. Such is found, clinically, to be the case. It frequently bappens that arterial tension is comparatively high when the left ventricle is inadequately filling the arteries; the arterioles in such cases contracting, and thus preventing the blood rushing into the veins with dangerous rapidity.

One may conveniently consider cases of this kind under three beads.

1. Cases in which the l.ft ventricle is itself imperfectly filled, and consequently uriable to pass on an adequate supply of blood to the arteries.-Chronic bronchitis, especially when accompanied by emphysema, affords a familiar instance of this. In chronic phthisis, again arterial tension may be high. I have often been struck by the frequency with which the radials are thickened in this disorder, and $I$ cannot but think it must be due to long-continued high tension. The radials may be quite large in these cases, and when tbis happens it must be assumed that the obstruction resides in the arterioles. In this connexion it is of interest to note that the accumulation of carbonic acid in the blood causes arterial constriction. Now such accumulation is practically always associated with imperfect filling of the left ventricle, owing to obstruction in the pulmonary circuit. Such is the case in suffocation, strangulation, and lung disease, in all of which it is therefore imperative that what little blood does pass into the systemic arteries should not flow too rapidly into the veins, which already hold far more than their share ; wherefore excess of carbonic acid in the blood is generally attended with the danger of empty arteries, and it is not surprising that the action of this substance on the vaso-motor system should be one tending to minimise this danger. Mitral obstruction may be mentioned as another disorder which prevents the proper filling of the left ventricle, and, as Sir Wm. Broad bent has insisted, it is almost always characterised by high tension.

2. Cases in which the left ventricle is dufective in driving power.- Fatty heart, in which high artelial tension has been observed, affords a striking instance; and scarcely less striking is the high tension of anæmia, in which the driving power of the left ventricle is certainly reduced, and in which fatty degeneration of the heart is not rare. This latter is especially frequent in pernicious anæmia, in which disorder I have seen the temporals markedly tense and tortuous, and that, too, when the patient was almost too weak to sit up in bed. I have observed exactly the same thing in extreme cases of marasmus in children. In typhoid fever, again, in which one is wont to expect very low tension, one may look in vain for it, even when the first sound is inaudible at the base and barely audible or inaudible at the apex, and when, therefore, it must be assumed that the driving power of the left ventricle is defective. It is by no means rare in such cases to find the radials "full between the beats," and I have at this moment under observation two cases of typhoid fever in children presenting the characteristic first sound just described, while the radial tension is good, the temporals are distended and tortuous-in one decidedly so-and the aortic sound quite loud.

3. Cases in which the imperfect filling of the arteries is due to aortio obstruction.-Tension may remain high in extreme forms of this disease. Thus in a case in which the orifice was reduced to a mere chink, the radial tensionalthough occasionally giving way-was well maintained to within a few weeks of death, and it has been experimentally shown that the aorta can be considerably constricted with. out modifying blood pressure. Doubtless the increased effort. of the left ventricle in such cases in part explains this, but: it does not, I think, entirely-as Cohnheim would appear to assume.

It is most important, when thinking of the venous circu lation, to bear in mind the fact that the driving power communicated to a fluid free to flow in tubes may speno itself wholly, or almost wholly, in carrying the fluid onwards and little or not at all by lateral pressure. Seeing that the venous pressure is low, one is apt to think of the driving energy of the venous blood as correspondingly low, and te wonder how so slight a pressure can carry on the venous circulation, forgetful of the fact that the driving energy of the venous blood spends itself chiefly in the forward direction. I have endeavoured to estimate the forward energy of the blood, as it flows through a large vein in which the lateral pressure is practically nil, by finding what head of pressure is required to drive water through the vein at the rate at which the blood flows through during life, and $I$ find that it is approximately equal to a column of water afrom twc to three feet in height. It is impossible to obtain mathematically aconrate results in this way, but the experiment suffices to show that even when the blood in the veins is exerting practically no pressure on the venous wall it may stil retain much of tbe energy communicated to it by the heart

Devonshire-street, Portland-place, W.

\section{A CASE OF MYXEEDEMA TREATED BY THYROID GLAND.}

BY JOHN HAROLD, M.R.C.S., L.R.C.P. LOND。 MEDICAL REGISTRAR, CHARIXG-CROSS HOSPITAL.

THE following notes with accompanying illastrations have reference to a case of myxodema which had failed to respond satisfactorily to the subcutaneous injection of a glycerine extract of the thyroid gland, but which was successfully treated by the oral administration of thyroid tabloids, and which illustrates the marked infiuence of the thyroid gland on dermic and epidermic structures.

A man fifty-one years of age was admitted into Charing cross Hospital suffering from myxodema. There was no history of antecedent depressing influences: there were no hardships, no worry, no injury. He was of temperate babits. The onset of the disease was gradual. He noticed that he was getting stouter, that he was clumsy in handling objects, that his feet were of en cold, and that for three or four years he was becoming weaker, and thus unable to follow his em ployment, which entailed hard work. For many years he had suffered from chilblains, and for three to four years his friends bad noticed the marked alteration in his face and in his general aspect. On coming under observation he presented the appearance characteristic of an advanced case of myxcedema. The face was swollen throughout and expressionless, and the ey ebrows were very thin and somewhat curiously arched. The nostrils were wide, the nose was flattened, and the a'x nasi were thickened, with obliteratic of the naso-labial fold. The hair of the scalp was exceed ingly thin and ory, and in many parts the scalp was quite bald. The tongue was enlarged and its movements were slow ; the teeth were loose, especially the molars; the gums were spongy and receding, and the lips much increased in size His skin was of a sallow tint, thickened, barsh and dry, with an absence of sebaceous secretion. There was an entire absence of hair in the axillæ and in the pubic region. Both hands and feet were sensibly enlarged, but not spade-like in appearance the nails were brittle and grooved and their nutrition was 
manifestly defective. There was an absence of skin lesions. His roice was husky; slowness of thought, of speech, and of movement were pronounced, and he appeared to take but little

\section{Fig. 1.}

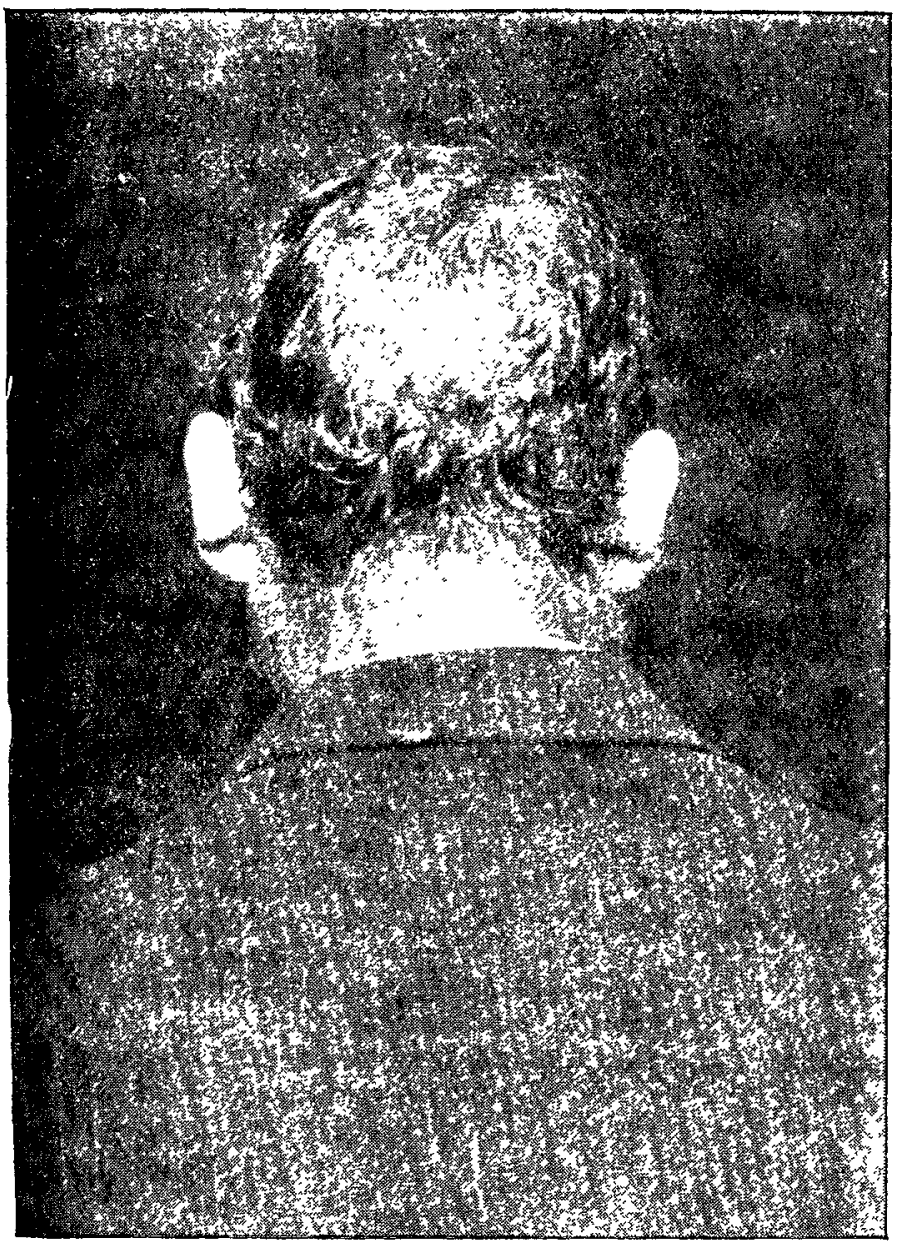

FIG. 2.

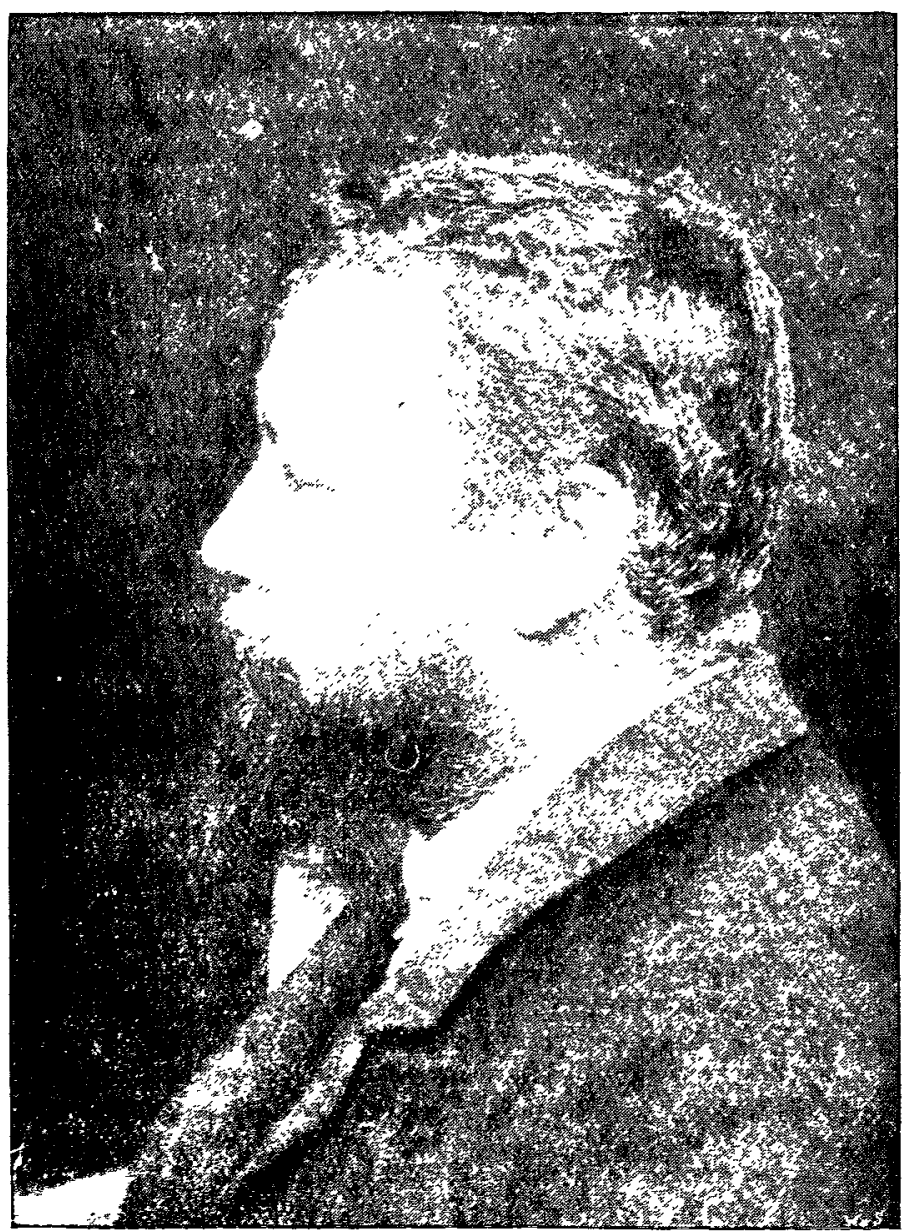

interest in what was going on around him. Awkwardness of gait, with associated incoördination of movement, was redidily perceived. The speech was accurate, but slow and thick ivision was normal, but somewhat interfered with owing to the swiolling of the eyelids ; there was no proptosis. A peculiar bibter taste and disagreeable odours were more or less constint troubles. The thyroid gland conld not be detected, and there were no correlated tumefactions in the supra-elavicular rejions. He was very sensitive to cold, but had no difficalty in swallowing. He was good tempered and had no illusions or hallucinations. Nothing abnormal was detected in w lungs, heart, or abdominal viscera. The urine was pate in colour, non-albuminous, and non-saccharine. The pulse ss slow and weak. The average temperature of $104 \mathrm{ob}$ ervations $=97.8^{\circ} \mathrm{F}$. The entire body was swollen and did not piten pressure.

ation The treatment first adopted was the subcutaneous injodistes of the back. No improvement following the injections, which were painful and caused abscesses, they were discontinuted, and when the abscesses had healed the oral administration of the thyroid gland in the form of tabloids was commenod.

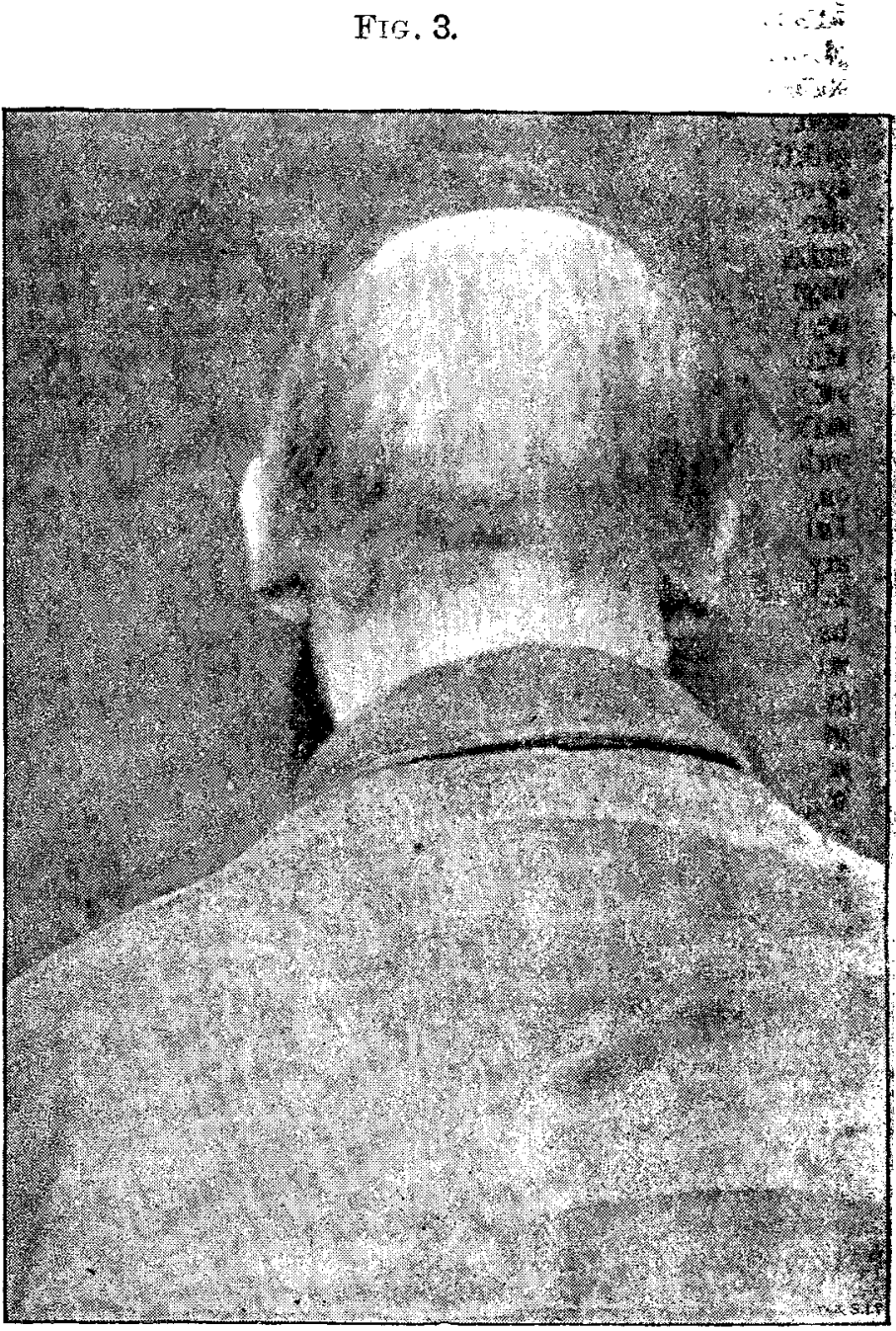

One to three tabloids (ive grains of the dried gland in eacu) were given daily, the patient being kept in bed thronghont the treatment and watch kept for any untoward effects. The tabloid form of administering the thyroid was selected as being reliable and more efficient than some of the powders and g]ycerine extracts of the gland. Improvement in the condition of the patient was soon manifested. His general appearance nrderwent a marked change: the abnormal myxodematons infiltration of the tissues gradually disappeared, his featares became unmasked; the skin became soft, less wax-like, and recovered its functions, perspiration of the hands being noted $t$ arly ; there was general desquamation, especially on the hands and feet, and the patient was brighter looking and generally more cheerful. There was a notable loss in veight. He no longer complained of cold or of the symptoms referable to the special senses already alluded to. An abundant growth of fine downy hair on the scalp was evident. The patient frequently mentioned the fact that he felt a peculiar tickling sensation in his throat, and, curionsiy, he located the site of this trouble over the situation of the thyroid gland. A peculiar mottling of the skin developed on 
the fole head. The urine becawe more abundant, of a higher colour, rich in pigments, and non-albuminous, with a vorlerately large mucous cloud; the excretion of urea was increased, the phosphoric acid elimination being normal in amount. 1 The hands regained their normal shape and their movements were much less clumsy. The improvewent in the mental faculties kept apace with the marked improvement in all his physical actions. The accompanying photographs, for which I gladly acknowledge my indebtedness to my friend Mr. V. A. L. Corbould, illustrate the malked improvement in the condition of the patient But striking as is the change effected, as shown by the illustrations, nothing but personal acquaintance could convey an idea of the physical and nental improvement which followed the administration of the thyroid gland. This case illustrates the difference between the effects prodaced by the subcutaneous and nral methods of administering this potent therapeutic agent. No amelioration of the symntoms followed the subcutaneous method, which the patien much objected to and which was attended by undesirable locil effects. Marked as are the favourable effects produced by the internal administration of the thyroid gland, it is of great importance to enjoin rest in bed during the course of treatment. The patient is thus kept in hand and any unpleasant $\in$ ffects produced by the remedy are early noted and sonn ohecked. The chief nntoward effects to be looked for are neurylgic pains, angina-like seizures, palpitations, depression, giddiness, nausea, and headache. Possibly many of these symptoms are referable to an idiosyncrasy on the part of the parient to the thyroid gland or to the dose administered being too large owing to there still being some functional thyroid gland left to carry on in part its internal secretion or, perha $\mathrm{Os}$, to stored-up waste products eliminated into the blood. It is therefore wise, especially if the patient be the subject of any cardiac trouble, to be satisfied with moderate inity doses, noting their $\in$ ffect on the temperature and puls:. As prima facie the rational treatment of myxoedema ougliti to be continuous, this patient was examined on $J \mathrm{oly} 16 \mathrm{th}$ last to ascertain if there was any recurrence of the myxcodema. He practically had discontinued the use of the tabluids since March, 1893. He informed me that he had not been so well for years and was able to follow his employment without any inconvenience whatever, that his appetite was gow. his skin had resumed its former colour and now perspired freely, the teeth were no longer loose, and chilly semistions, bitter tastes, and unpleasant odours no longer trcubled him. His manner was alert, his locomotion rapid, and his speech quite natural, and he boasted of the luxuriant growth of hair on the head. It was therefore manifest that in this case the degree of improvement obtained under the thyroid treatment was maintained. He still continues under obiervation. so that, if necessary, the tabloids may be resumed. Now that we know the pathology of myscedema and its successful treatment by thyroid gland there remain hut, to know its inilial cause and its prodromata.

I lave to thank Dr. Mitchell Bruce for kind permission to publish this case.

Haxdey-streat, $W$

\section{A CASE OF TRAUMATIC STRICTURE OF THE URETHRA.}

Br W. H. BROWN, M.R.C.S.

"'Fn following history seems to me worthy of record as a contribution to the subject of tranmatic stricture of the urethra and its treatment. Viewed as such it has the disadrantace of bringing forward but a single case; but, on the other hand, it has the advantage that the case presented is pecial opportunities for complete and accurate report.

A fine, healtby, strongly built man twentv-five years of age was first seen by me on Dec. 11th, 1892. I Iis story was that hout $4 \mathrm{P}$.3. on the previous day, whilst crossing a stile, his foot slipped and he fell astride on the top bar. He was a litile bruised, but did not feel much pain, and walked about as usual, bat from the time of the fall he was unable to pass any urine. A little blood came from the urethral orifice once or twice. On the morning following the accident he walked up to : ce my partner. Mr. Foster. The latter attempted to puss a catbetej-first a sott rubber one, then an olivary gum elastic one, then a silver one,--but he could not pass a point about four inches from the meatus. A good deal of bleeding took place. There was then some ecchymosis about the scrotum and for about an inch behind it. The bladder was halfway up to the umbilicus, and there was a desire to micturate. The patient was sent home to bed, and at 12.30 P.M. I saw him with Mr. Foster. J verified the above appearances, but did not attem pt to pass a catheter. The patient had then passed no urine for twenty hours. We arranged to give him chloroform in an hour's time and to do what might be necessary. But half an hour after we had left him the patient walked to my house and informed me that he had just passed more than a pint of urine, naturally with a little blood, but with scarcely any pain. He was sent home to rest in bed. On the next day (Dec. 12th) he seemed to be well. A spot was noted in the perineum, just behind the scrotum, which was tender and slightly swollen. Pressure on this spot caused a few drops of blood to escape from the urethral orifice. After this the patient seemed to go on well; there was no fever, and only slight pain after micturition. On the 17 th it was noted that on two occasions about an egg-cupful of blood had come from the urethra. "Has little pain now; micturates without difficulty." Four days later a hardish swelling about as big as a pigeon's egg, situated just behind the scrotum, " seemed to burst into the tube after his passing urire, and a lot of dirty stuff came away." The next note relating to the case is dated just six months later-viz., June 23rd, 1893ard runs as follows: "The patient did not come for advice or treatment (he was always very frightened of tbe catheter), but on being met and questioned yesterday he stated that he is having a good deal of trouble with his urine lately. He says be felt nothing unusual for three months after the accident, but since then there has been gradually increasing difficulty. At present he has to micturate rather frequently (five or six times a day, he says), and it takes him some time to void all he can (perhaps five minutes). $\mathrm{He}$ is generally up once or twice at night. He says there is barely a continuous stream now, most of the urine coming in little drops. A little urine often dribbles away between times. He says he micturates most successfally on first getting out of bed in the morning." On examination slight hardening and thickening were felt in the course of the urethra in the hinder part of the scrotum. On percussing above the pubes (half an hour after micturition) the dulness was found to extend two or three inches upwards. Next day, the patient being in bed, an attempt was made to pass an instrument. Various kinds were tried in succession, but they all stopped absolutely at a point four inches from the meatus. On June 30th it was noted : "Since last note several attempts have been made to get through the stricture, but not even the finest whalebone bougie could be coaxed through. The urine can only be passed by drops and it dribbles away almost continuously." On this date I performed external urethrotomy according to Mr. Wheelhouse's plan. With a good light, and with the cut edges of the urethra held apart by silk threads, there was not too much difficulty in finding the way into the stricture with a small probe. This was replaced with a little more trouble by a small director, and the very tight stricture was then slit up with a probe-pointed bistoury. With the help of Teale's gorget a No. 10 silver catheter was passed from the meatus urinarius into the bladder and tied in. The following evening, as the patient complained of a little pain, the silver catheter was withdrawn and immediately replaced by a gum elastic one of the same size. On July 4 th the catheter was renuoved. The patient had been keeping quite well. On July 5 th an attempt was made to pass the silver catheter; it was unsuccessful, and some bleeding occurred both from the meatus and the perineal wound. Next day, another attempt to pass a catheter having failed, the patient was again put under ether. the perineal wound opened with the finger, and a No. 12 (English) passed the whole length of the urethra into the bladder withont much difficulty. It seemed as though the difficulty had arisen through the point of the instrument slipping out of the urethra at the wound and passing into the tissues below it. A No. 12 gum catheter was tied in. On Jaly 12 th it was noted: "Two days ago the No. 12 catheter slipped out. Since then, on two occasions a careful and prolonged attempt has been made to get an instrument into the bladder. Soft, coudé, and silver catheters of various sizes were tried, but witbout success. Free bleeding was easily induced. 'This morning I saw the patient pass urine; the stream was full and free, better than it ever had been since 